\title{
Experimental investigation on the production of bio-oil from maize straw at a pilot scale
}

\author{
N. S. Rathore', Arjun Sanjay Paul' ${ }^{2}$, N. L. Panwar ${ }^{2+}$ \\ ${ }^{1}$ Vice Chancellor, Maharana Pratap University of Agriculture and Technology, Udaipur (Rajasthan) 313001 India \\ ${ }^{2}$ Department of Renewable Energy Engineering, College of Technology and Engineering, Maharana Pratap University of Agriculture and Technology, \\ Udaipur (Rajasthan) 313001 India
}

\begin{abstract}
The production of biofuel from agricultural crop residue via fast pyrolysis is becoming a popular option. It can help to build a robust renewable fuel market and ensure environmental sustainability. In this study, the widely available maize straw was used for the production of bio-oil in a fluidized bed reactor at a pilot scale. The effect of pyrolysis parameters such as temperature, biomass particle size, and carrier gas flow rate on the production of bio-oil, char, and syngas was investigated. The maximum bio-oil yield of 44.6 wt. $\%$ was achieved at a pyrolysis temperature of $500^{\circ} \mathrm{C}$. The physicochemical properties of bio-oil were determined, and the heating value was found to be $18.5 \mathrm{MJ} / \mathrm{kg}$. Furthermore, the chemical composition of maize straw bio-oil was analyzed by GC-MS and FTIR. The compounds such as phenol (22.83\%), carboxylic acids (27.36\%), ketone $(19.14 \%)$ alcohols $(2.09 \%)$, esters, furfural, hydrocarbon and aromatic compounds, etc. were identified in the bio-oil. The cost analysis of the developed system showed that the cost of production of bio-oil from maize straw was $0.47 \mathrm{US} \$ / \mathrm{L}$ and the calculated payback period was 1.47 year.
\end{abstract}

Keywords: Bio-oil, Char, Fast pyrolysis, Fluidized bed, Maize straw

\section{Introduction}

Energy is the basic need, with an increase in economic development and the population leads to a high demand for energy globally. However, the demand for energy increased by 2.3 percent from 2010 to 2018 both in terms of conventional and non-conventional fuels, and consequently, it causes an increase in carbon emission by 1.7 percent [1]. Bio-energy is one of the promising forms of renewable energy, gaining attention globally due to its easy availability and conversion into various forms of fuel. It is being categorized mainly into two types, traditional and modern bioenergy. The traditional bio-energy mainly used to produce heat via combustion from biomass such as wood, charcoal, and organic waste. However, the modern bio-energy consisted of the production of liquid fuel (biofuel), biogas from agricultural waste and bio-refineries, etc. According to the International Energy Agency (IEA) report; the modern bio-energy will be receiving its peak growth between 2018 and 2023 [1].

Biofuel such as bio ethanol and biodiesel has been conceding as the best alternative option to fossil fuel. The share of biofuel in the transport sector in 2018 was about $3.7 \%$ with a contribution of 4 EJ. However, the yield of biofuel is forecasted to increase $25 \%$ during 2020-24, to reach 190 billion litres [2]. Lignocellulosic biomass such as agricultural residues is becoming a promising option to strengthen bioenergy production [3]. Currently, the total share of agriculture residue in total bioenergy production is about $3 \%$. The energy potential of agricultural residues lies in the range of 17.8 to 82.3 EJ. The crops such as maize, rice, and wheat have a major contribution to the production of agricultural residue [4]. Annually, 140 billion MT of biomass is generated globally from agriculture [5]. Maize is acknowledged as the queen of cereal crops because of its quality and demand. The annual global production of maize was about 1040 million MT in the year 2016-17. The U.S.A and China are the top growers of the maize with a contribution of $38 \%$ and $23 \%$, respectively [6]. It is reported that every $\mathrm{kg}$ of dry maize grain produces $0.5 \mathrm{~kg}$ of stalk [7] and the properties of stalk also showed great potential as an energy source [8, 9]. Many developing countries are producing an enormous amount
This is an Open Access article distributed under the terms of the Creative Commons Attribution Non-Commercial License (http://creativecommons.org/licenses/by-nc/3.0/) which permits unrestricted non-commercial use, distribution, and reproduction in any medium, provided the original work is properly cited.

Copyright (C) 2022 Korean Society of Environmental Engineers
Received October 27, 2020 Accepted December 24, 2020

${ }^{\dagger}$ Corresponding author

E-mail: nlpanwar@rediffmail.com

Tel: +912942471068 Fax: +91 2942471056

ORCID: 0000-0002-3309-2306 
of crop residues. These residues possess the potential to be used as feedstock for renewable fuel production. Moreover, either these residues are used as fodder or are burned and left at the field unutilized.

The thermochemical conversion of agricultural residue/waste into biofuel is becoming one of the emerging fields of research. Combustion, gasification, and pyrolysis are the main three types of thermochemical conversion methods. Gasification process used to convert the biomass, mainly into gaseous fuel called as syngas or producer gas. Whereas pyrolysis can convert the biomass into three forms of fuels, i.e. solid (bio-char), liquid (bio-oil), and gas (syngas) [10]. The gasification requires high temperature (900-1,00 $0^{\circ} \mathrm{C}$ ) and performs well when biomass is in the solid form like briquettes or densified biomass. However, pyrolysis requires medium temperature $\left(400-600^{\circ} \mathrm{C}\right)$ and dry-loose biomass can be treated. For the conversion of agricultural biomass into fuel pyrolysis process is found most easy, efficient and economical than the other thermo-conversion methods [11]. However, the yield of these products may depend upon the process conditions such as temperature, biomass, and residence time. These produced products have the potential to be used as fuel in many applications. Recent studies found that fast pyrolysis as an optimistic method to convert biomass into bio-oil (biofuel) [12]. The fast pyrolysis process is accomplished by rapid heating of biomass in the absence of oxygen to yield liquid (60-70\%), solid (30-40\%), and gas (20-30\%) [13]. The produced bio-oil is a dark brown viscous liquid contains very low sulphur and nitrogen but very high oxygen i.e. nearly 40 wt.\% [14]. It can be used as fuel in boiler, engines, and turbines for heat and power generations [15, 16], and after upgrading it can be used as a transport fuel. The bio-oil contains many chemical compounds like acids, ketones, phenols, sugar, alcohols, and esters. Accordingly, it is possible to produce chemicals from bio-oil such as food flavourings agents, acetic acids, aromatics, resins, agrochemicals, and fertilizers [17]. The by-products of pyrolysis such as char and syngas can be used as soil amendment, biochar-derived fertilizers, wastewater filtration systems, and fuel, respectively [18]. However, the utilization of agricultural residues as a feedstock for the production of quality bio-oil from fast pyrolysis process was studied by many researchers, and the types of feedstocks were used such as Corn straw [19], Rice husk [20], Sugarcane bagasse [21], Coconut shell [22], Peanut shell [23], Cotton stalk [24], Cherry seed shell [25], and Grape seeds [26]. It is a well-known that the biomass is green and $\mathrm{CO}_{2}$ neutral fuel as well as the fuel produced from biomass such as bio-oil, biochar, etc. also cited as carbon neutral. The amount of $\mathrm{CO}_{2}$ emitted during the combustion of bio-fuel is same as the amount of $\mathrm{CO}_{2}$ consumed by biomass during the growth.

Despite the enormous availability and potential agricultural residues remains unutilized and become a cause of pollution, by burning at an open field. The conversion of agricultural waste into fuel or value-added chemicals is one of the emerging fields of research. The maize is one of the most grown crops in the world and maize straw possesses the properties feasible for fast pyrolysis like high volatile matter. Besides, the previous published work associated with agricultural waste is limited to small, laboratory scale, or it is theoretically proven, and have not discussed the economic analysis. A great extent of work has been done on to identify the potential of different biomass such as forest, organic, agricultural waste and development of new techniques to produce bio-oil. Therefore, the proposed study was aimed to investigate the feasibility of maize straw as feedstock for the production of biofuel i.e. bio-oil and biochar at a pilot scale with concentrating on the techno-economic analysis. The effect of varying pyrolysis conditions on the yield of bio-oil, char, and syngas were analyzed to determine the optimum operating condition. The detailed analysis of bio-oil properties indicates its potential as fuel or value-added chemical. The chemical composition of maize straw bio-oil was assessed by the Gas Chromatography-Mass Spectrometry (GC-MS) and Fourier Transform Infrared Spectroscopy (FTIR) analysis. The storage stability of bio-oil was also studied to investigate the change in physical properties at storage condition. However, the present study will help farmers or entrepreneurs to study the production and cost estimation of a bio-fuel at their farm. It is a high time to find a sustainable and economic option which can produce a renewable fuel from biomass/agricultural waste.

\section{Experimental Methods}

\subsection{Feedstock Selection}

The maize straw used as feedstock for the fast pyrolysis process, and it was collected from the farm of the College of Technology and Engineering, MPUAT, Udaipur, Rajasthan, India. The maize straw was dried in the solar tunnel dryer for 4-5 $d$ to decrease its moisture content below $10 \%$ and then crushed using a mill to get biomass particle size in the series of 1 to $3 \mathrm{~mm}$.

\subsection{Characterization of Maize Straw}

The proximate and ultimate characteristics of the maize straw, including heating value were determined using ASTM standards, as suggested by Basu [27]. The composition of biomass, i.e. cellulose, hemicellulose, and lignin were determined using thermogravimetric analysis results (TGA). TGA helps to study the mass loss that occurs during the pyrolysis process with increasing temperature. The TGA Model- STA7300 (Hitachi, Germany) used for the present study.

\subsection{Experimental Setup and Procedure}

The fluidized bed fast pyrolysis system with a throughput capacity of $5 \mathrm{~kg} / \mathrm{h}$ designed and developed for the present experimental work at the College of Technology and Engineering, MPUAT, Udaipur, Rajasthan, India. The pictorial view of the developed fast pyrolysis system is shown in Fig. 1. The developed fast pyrolysis system has the following subparts, biomass feeder, fluidized bed reactor (FBR), cyclone separator, and condenser. The reactor was externally heated with the help of an electric heater of $2.5 \mathrm{~kW}$ capacity. The reactor of $1.3 \mathrm{~m}$ height and $0.3 \mathrm{~m}$ diameter was designed to carry $5 \mathrm{~kg} / \mathrm{h}$ of biomass. The biomass feeding system was operated with a variable speed motor to regulate and supply biomass continuously. The sand of diameter $0.6-0.7 \mathrm{~mm}$ was used as bed material and $\mathrm{N}_{2}$ gas used as a fluidizing medium. The $\mathrm{N}_{2}$ gas passed with pressure at desired fluidization velocity through the bottom of the reactor and part of $\mathrm{N}_{2}$ was also supplied to the biomass feeder, to avoid clogging of biomass at biomass feeder. 


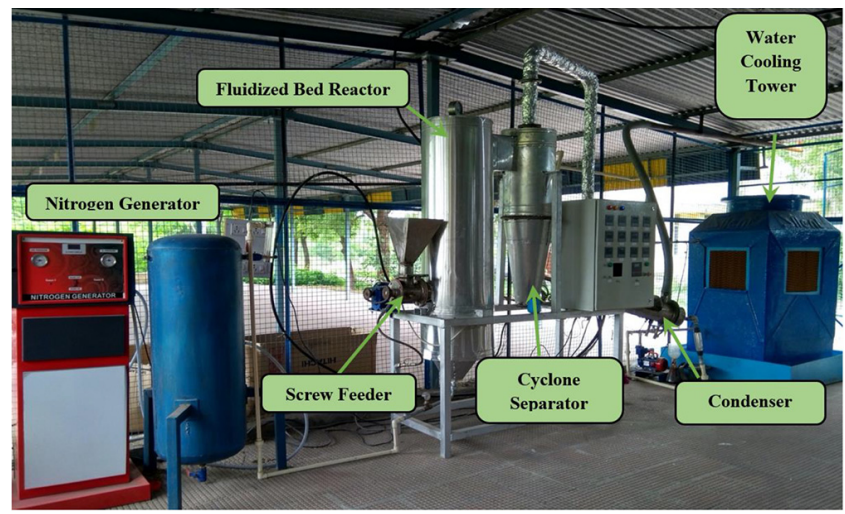

Fig. 1. Developed fluidized bed fast pyrolysis system.

The cyclone with dimensions of height $1.2 \mathrm{~m}$ and a diameter of $0.3 \mathrm{~m}$ was designed, to collect the char and passed the clean vapour to the condenser. The water-cooled condenser was designed with a length of $1.3 \mathrm{~m}$ and a diameter of $0.168 \mathrm{~m}$. The detailed experimental setup was presented in our previous research article [28]. In order to assess the performance of developed fluidized bed fast pyrolysis system, each experimental trial was repeated three times. The experiments were performed with varying temperatures from $400,450,500,550$ and $600^{\circ} \mathrm{C}$, carrier gas flow rate from $2.5,3.0,3.5$, and $4.5 \mathrm{~m}^{3} / \mathrm{h}$ and biomass particle size from 1,2 , and $3 \mathrm{~mm}$. The effect of varying these pyrolysis conditions was studied on the percentage yield of bio-oil, char and syngas and it was calculated by using the following equations.

$$
\begin{gathered}
\text { Bio }- \text { oil yield }=\frac{\text { weight of bio-oil }(\mathrm{g})}{\text { raw biomass }(\mathrm{g})} \times 100 \% \\
\text { char yield }=\frac{\text { weight of char }(\mathrm{g})}{\text { raw biomass }(\mathrm{g})} \times 100 \% \\
\text { syngas yield }=100-(\text { Bio }- \text { oil }+ \text { Char yield })
\end{gathered}
$$

\subsection{Characterization of Bio-Oil}

The bio-oil obtained under optimal pyrolysis conditions was selected for the characterization. The different physical properties of bio-oil such as density, viscosity, acidity, and heating value were determined using respective standard methods. The water content was measured by the Karl Fisher titration method. The $\mathrm{C}, \mathrm{H}, \mathrm{N}$, and $\mathrm{O}$ content of bio-oil was analyzed by using the elemental analyzer. The available chemical compounds in bio-oil were identified by GC-MS and FTIR analysis. The GC-MS model- Shimadzu, QP-2010 and FTIR model- Thermo Scientific, Nicolet iS50 NIR was used for the present study. In the GC-MS analysis, the specifications of capillary column such as length and inner diameter are directly related with separation efficiency. Therefore, the capillary column with short thickness and small internal diameter is mostly preferred. In this study, the capillary column of DB-5 with thickness of $0.25 \mu \mathrm{m}$ film with length $30 \mathrm{~m}$ and diameter $0.25 \mathrm{~mm}$ was used. The carrier (helium) gas flow rate was kept at $1 \mathrm{~mL} / \mathrm{min}$ for the better separation of components. Initially, the temperature of oven was maintained at $70{ }^{\circ} \mathrm{C}$ for $2 \mathrm{~min}$ and then gradually increased to $250^{\circ} \mathrm{C}$ at the heating rate of $5^{\circ} \mathrm{C} / \mathrm{min}$. The storage stability of the bio-oil was also studied to assess its change in physical properties i.e. viscosity after storing it at room temperature

\subsection{Cost Analysis}

The cost analysis of bio-oil production from maize straw using $5 \mathrm{~kg} / \mathrm{h}$ biomass carrying capacity system was assessed by calculating economic measures such as payback period, net present value, benefit-cost ratio, and internal rate of return.

\section{Result and Discussion}

\subsection{Characterization of Maize Straw}

The properties and elemental composition of maize straw are shown in Table 1. The moisture content of biomass is the most crucial parameter which would seriously affect the yield and quality of bio-oil produced. It is observed that the biomass with less moisture gave maximum bio-oil yield as well as persuade high conversion efficiency [29]. The available moisture in maize straw is $7.2 \mathrm{wt} . \%$, which is found appropriate for fast pyrolysis. The percentage of the volatile matter of biomass directly linked with bio-oil yield, more volatile matter content of biomass is preferable for bio-oil production [30]. The maize straw has 77.6 wt.\% of volatile matter, and it is recorded higher than cotton stalk [31] and rice husk [32]. The high ash in biomass leads to lower down the bio-oil production, therefore biomass with lower ash content should be preferable [33]. The maize straw has very high ash content i.e. 5.90 wt.\%. Another biomass important component such as cellulose (33.19\%), hemicellulose (25.20\%), and lignin (15.27\%) were observed in a maize straw. The calorific value of maize straw was calculated as $17.26 \mathrm{MJ} / \mathrm{kg}$, which is higher than cotton stalk [24], rice husk [32], and bagasse [34].

Table 1. Characteristics of Maize Straw

\begin{tabular}{lc}
\hline Properties & Content (\%) \\
\hline Proximate analysis & 7.2 \\
Moisture content & 77.6 \\
Volatile matter & 14.2 \\
Fixed carbon content & 5.90 \\
Ash Content & 17.26 \\
HHV (MJ/kg) & \\
Ultimate analysis & 47.42 \\
C & 6.41 \\
H & 1.03 \\
N & 45.14 \\
O & \\
Composition & 35.7 \\
Cellulose & 26.5 \\
Hemicellulose & 18.4 \\
Lignin &
\end{tabular}




\subsection{Thermogravimetric Analysis (TGA) of Maize Straw}

Thermogravimetric analysis (TGA) has been widely used to study the mass loss takes place through the pyrolysis process. Fig. 2 depicted the thermal degradation of maize straw as function of temperature and time. It is clear that the elimination of moisture from maize straw initiated from temperature 110 to $200^{\circ} \mathrm{C}$. However, the major mass loss occurred from temperature $150^{\circ} \mathrm{C}$ to $500^{\circ} \mathrm{C}$. It was observed that the cellulose, hemicellulose, and lignin of biomass starts to degrade from $250-500^{\circ} \mathrm{C}$. The main conversion of biomass into pyrolysis products happened here, it's called as active pyrolysis stage. Besides, hemicellulose was the first component that start to decompose from $250^{\circ} \mathrm{C}$ and over to $400^{\circ} \mathrm{C}$. Cellulose component decomposition observed between temperatures from $350-420^{\circ} \mathrm{C}$, and the similar type of trend was reported by Zhao et al. [35]. The degradation of lignin is the complex part of biomass degradation, and it was observed that its decomposition initiated from temperature nearly about $200^{\circ} \mathrm{C}$ and ends to $900^{\circ} \mathrm{C}$, supported by Mythili et al. [36]. The removal of volatile matter i.e. $78.52 \%$ occurred between temperatures 250 to $500^{\circ} \mathrm{C}$, i.e. from active pyrolysis stage.

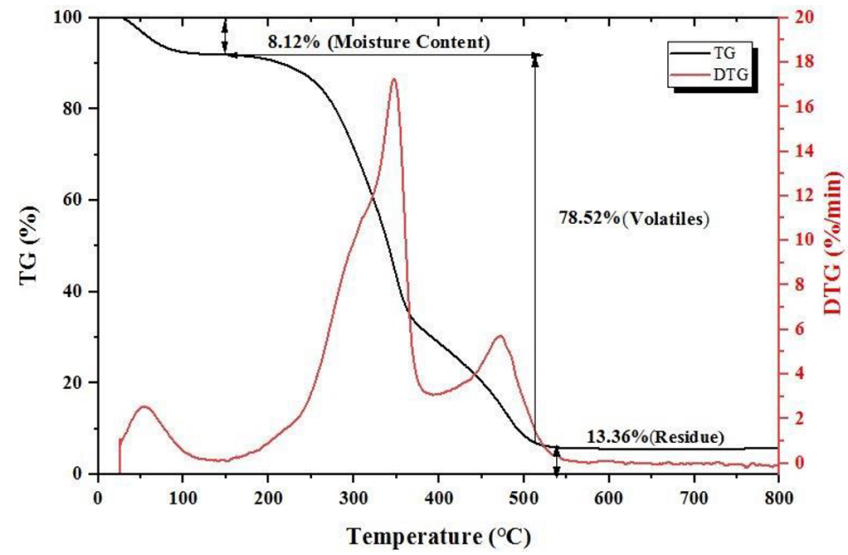

Fig. 2. Thermogravimetric curve for maize straw.

\subsection{Effect of Temperature on Yield of Pyrolysis Products}

The temperature is a crucial parameter of the fast pyrolysis process. The effect of varying temperature from 400 to $600^{\circ} \mathrm{C}$ on pyrolysis products bio-oil, char and syngas was studied and results shown in Fig. 3. It can be seen that, bio-oil yield increases from 31.2 to 44.6 wt.\%., by way of temperature increases from 400 to $500^{\circ} \mathrm{C}$. The maximum char yield of 38 wt.\% was obtained at a temperature of $400^{\circ} \mathrm{C}$ and it gradually decreases to 27.6 wt.\%., by increasing temperature to $600^{\circ} \mathrm{C}$. It was observed that, the yield of bio-oil decreases 44.6 to 34.2 wt.\% and gas yield increases 24.4 to 38.5 wt.\%, by the way of temperature increases 500 to $600^{\circ} \mathrm{C}$. The maximum yield of bio-oil of 44.6 wt.\% was recovered from maize straw at pyrolysis temperature of $500^{\circ} \mathrm{C}$. The increase in gas production at elevated temperature may be due to secondary cracking reaction of bio-oil takes place at this temperature, as well as with increasing temperature the conversion of carbon to gases also escalated [13]. However, at lower temperature primary pyrolysis takes place and with increasing temperature the char yield start to deceases [37]. The same type of results were reported for the fast pyrolysis of jatropha oil cake [38] and rapeseed [39].

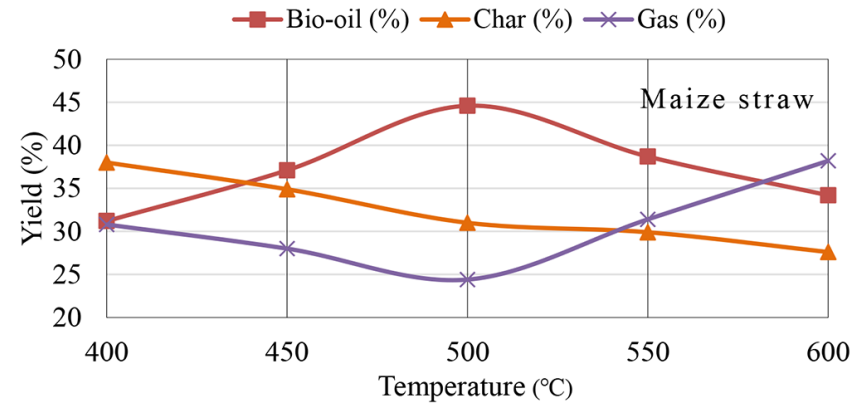

Fig. 3. Effect of temperature on pyrolysis products.

\subsection{Effect of Biomass Particle Size on Yield of Pyrolysis Products}

The selection of suitable biomass particle size for fast pyrolysis is a critical step, because it can directly affect the heat and mass transfer rate. In this study, the effect of biomass particle size on the yield of pyrolysis products were presented. The biomass particle size from 1 to $3 \mathrm{~mm}$, pyrolysis temperature of $500^{\circ} \mathrm{C}$ and gas flow rate of $4.0 \mathrm{~m}^{3} / \mathrm{h}$, were used for this run. It can be seen from Fig. 4, that the smallest biomass size $1 \mathrm{~mm}$, delivered maximum yield of bio-oil 44.6 wt.\% from maize straw. Besides, it is found that with increasing particle size from 1 to $3 \mathrm{~mm}$, the bio-oil yield decreases from 44.6 to 31.4 wt.\%. However, the yield of both char and gas was found increased from 31.0 to 33.2 wt.\% and 24.4 to 35.4 wt.\%, respectively by way of increasing particle size. The same type of findings were obtained from the study of Madhu et al. [40]. The results were due to that the smaller biomass particle size more is heat transfer rate and thus it causes to rapid thermal degradation of biomass at smaller particle size. On the other hand, larger biomass tends to slower down the heat transfer rate and increases residence time that causes to conversion of biomass to char [41]. However, particle size of $1 \mathrm{~mm}$ [24] and $2 \mathrm{~mm}$ [42] were reported best for maximum bio-oil production. But many studies also found that there is no such effect of biomass particle size on pyrolysis products.

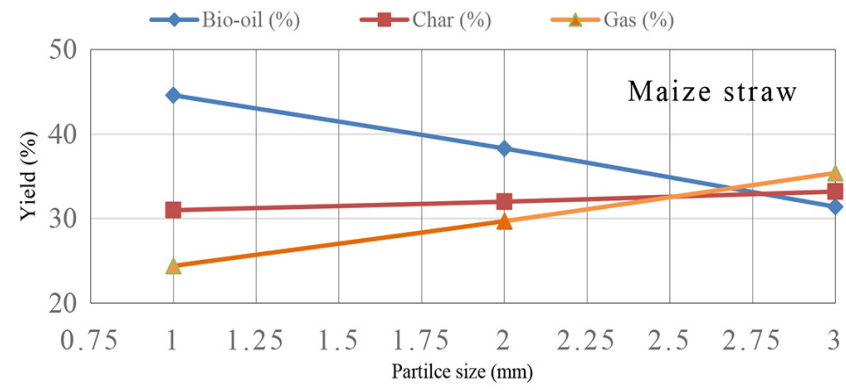

Fig. 4. Effect of particle size on yield of pyrolysis products.

\subsection{Effect of $\mathrm{N}_{2}$ Gas Flow Rate on Yield of Pyrolysis Products}

The role of carrier gas is to remove the pyrolysis vapours quickly, regulate the vapour residence time. The flow of $\mathrm{N}_{2}$ was varied in the range of 3.0 to $4.5 \mathrm{~m}^{3} / \mathrm{h}$, to assess the effect on pyrolysis products at temperature of $500^{\circ} \mathrm{C}$. 


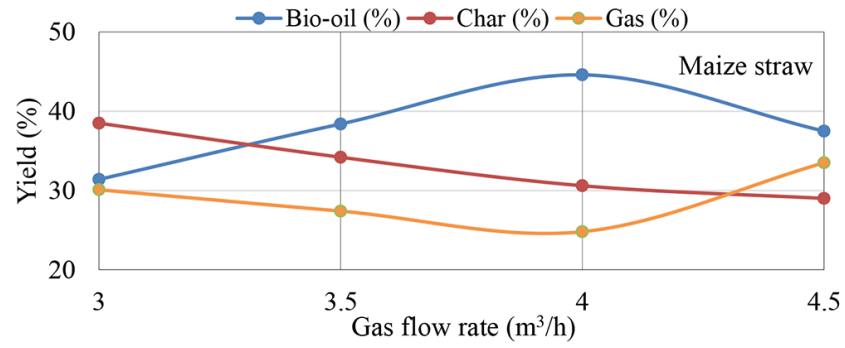

Fig. 5. Effect of $\mathrm{N}_{2}$ Gas flow rate on yield of pyrolysis products.

Fig. 5 clearly shows that, with increasing $\mathrm{N}_{2}$ flow rate from 3.0 to $4.0 \mathrm{~m}^{3} / \mathrm{h}$, the bio-oil yield start increases from 31.4 to 44.6 wt.\%, and it decreases as the flow of $\mathrm{N}_{2}$ increases above $4.0 \mathrm{~m}^{3} / \mathrm{h}$. It is seen that, the syngas yield increased from 30.1 to 33.5 wt.\% and char yield decreased from 38.5 to 29.0 wt.\% by increasing gas flow rate. It is also observed that the yield of syngas increased swiftly from 24.8 to 33.5 wt.\% as the gas flow rate increased beyond $4.0 \mathrm{~m}^{3} / \mathrm{h}$ i.e. optimum flow rate. The results obtained are found similarity with work of Ali et al. [43]. The maximum bio-oil yield of 44.6 wt.\% was obatined at $\mathrm{N}_{2}$ flow rate of $4.0 \mathrm{~m}^{3} / \mathrm{h}$. It was concluded that the higher flow rate leads to higher bio-oil yield and lower char yield. Because at low gas rate, the vapour residence time gets extended and secondary reactions causes to convert biomass into char and gas [44]. However, the flow rate of sweep gas beyond optimum value i.e. $4.0 \mathrm{~m}^{3} / \mathrm{h}$ give rise to high yield of syngas (inclusive of condensable and non-condensable gas) [28].

\subsection{Characterization of Bio-Oil}

The bio-oil has very distinct properties and before to use it as a fuel, characterization is required. However, bio-oil has same nearly the same elemental composition to the original biomass feedstock. The physical and chemical characteristics of bio-oil produced from maize straw at pyrolysis temperature of $500^{\circ} \mathrm{C}$, were presented in Table 2 with respective standard methods. Generally, the bio-oil produced from biomass contains high amount oxygen due to the presence of oxygenated compounds which originated from the cellulose and hemicellulose components of biomass. The maize straw bio-oil contains 43.2 wt.\% oxygen, which is found very high as compare to diesel fuel [22]. The maize straw contains high percentage of water i.e. 32.7 wt.\%. The water content of bio-oil is directly linked with the intimal moisture content of raw biomass and reactions takes place during pyrolysis process. The typical bio-oil contains water in the range of 15-50 wt.\% [13] and according to bio-oil norms and standard ASTM D 7544 for Grade D and G bio-oil (pyrolysis oil), the $25-30 \%$ water content is allowed to use as fuel in turbine and boiler [45]. The viscosity of fuel is the important property, played vital role in processing and handling of fuel. The viscosity of bio-oil was measured at a temperature of $40^{\circ} \mathrm{C}$, and it was found to be $21.0 \mathrm{cSt}$. The density of maize straw bio-oil was found to be $1,145 \mathrm{~kg} / \mathrm{m}^{3}$, both density and viscosity were found high and it may be due to the high content of water. It was reported that the bio-oil viscosity at room temperature tends to decrease with time, hence the aging study of maize straw bio-oil was undertaken to see the effect of storage time on viscosity of bio-oi. The produced bio-oil found acidic in nature with $\mathrm{pH}$ of 3.1 and the energy value of bio-oil was determined to be $18.5 \mathrm{MJ} / \mathrm{kg}$, which is found higher than rice husk [20] and similar with sugarcane bagasse [21].

\subsection{Chemical Composition of Bio-Oil}

The available chemical groups in the bio-oil were identified using (FTIR), and Fig. S1 shows FTIR spectra of maize straw bio-oil. The first and very small peak between $3,650-3,300$ given to the $\mathrm{O}-\mathrm{H}$ stretching bond, indicated the existence of alcohols and phenols compound. The major peak between 3,550-3,200 indicate the presence alcohols (O-H group). Another small peak between 3,050-2,800 given to the $\mathrm{C}-\mathrm{H}$ stretching bond, indicated the alkanes group. The peak 1,644.9 confirmed the presence of alkenes group with $\mathrm{C}=\mathrm{C}$ stretching. However, the peak between 1,500-1,400 given to the $\mathrm{O}-\mathrm{H}$ bending indicated the carboxylic acids presence. The peak 1,342-1,266, 1,210-1,163, and 1250-1010 given to the C-N, C-O, and, C-N stretching shows the presence of aromatic amine, amine and esters group, respectively. FTIR functional groups with class of compounds available in maize straw bio-oil are presented in Table 3. Previous studies shows that nearly similar type of functional groups were obtained using FTIR of bio-oil [46-48].

The GC-MS analysis was carried out to identify the chemical compounds available in bio-oil produced from maize straw. The bio-oil contains several type of organic compounds. Total 82 type of compounds were identified in the maize straw bio-oil using GC-MS NIST library. However, following major groups such as

Table 2. Properties of Bio-Oil

\begin{tabular}{lccc}
\hline Properties & Maize straw & Rice husk [19] & Diesel [21] \\
\hline Water content (wt\%) & 32.7 & 35 & - \\
Density (kg/m³) (ASTM D 4502) & 1145 & 1167 & 840 \\
pH & 3.3 & 3.22 & - \\
Viscosity, cP @ 40C (ASTM D 445) & 21.0 & 9.8 & $2.1 @ 50^{\circ} \mathrm{C}$ \\
Heating value (MJ/kg) (ASTM D 240) & 18.5 & 17.20 & 40 \\
C (wt\%) & 47.9 & 31.63 & 86.5 \\
H (wt\%) & 6.4 & 8.7 & 13.2 \\
O (wt\%) & 43.2 & 48.12 & 0.01 \\
N (wt\%) & 0.9 & 0.5 & $\mathrm{pm}$ \\
\hline
\end{tabular}


Table 3. FTIR Functional Group of The Maize Straw Bio-Oil

\begin{tabular}{lccc}
\hline Frequency range & Frequency & Group & Class of compounds \\
$3,650-3,300$ & $3,619.4$ & N-H & Amines \\
$3,550-3,200$ & $3,315.2$ & O-H Stretching & Alcohols \\
$3,050-2,800$ & $2,949.0$ & C-H Stretching & Alkanes \\
$1,662-1,626$ & $1,644.9$ & C=C Stretching & Alkenes \\
$1,500-1,400$ & $1,386.9$ & O=H bending & Carboxylic acid \\
$1,342-1,266$ & $1,281.8$ & C-N Stretching & Aromatic amine \\
$1,210-1,163$ & $1,146.4$. & C-O Stretching & Esters \\
$1,250-1,010$ & $1,031.8$ & C-N Stretching & Amine \\
\hline
\end{tabular}

phenol (22.83\%), carboxylic acids (27.36\%), ketone (19.14\%) alcohols (2.09\%), esters, furfural, hydrocarbon and aromatic compounds etc. were identified in the bio-oil, shown in Table S1.

Moreover, the oxygenated compounds namely acids, aldehydes, alcohol and phenol are the main influencer in the bio-oil. It was reported that the phenols and aldehyde causes the thermal instability in bio-oil [49]. Recently, more research is being conducted to extract the chemical compounds from bio-oil which can be used to produce hydrocarbon fuels via upgrading and value added chemicals [50, 51]. The separated compounds from bio-oil e.g. acetic acid, carboxylic acids, phenol, furans, and dimers, etc. can be used as feedstock in biorefinery [52].

\subsection{Storage Stability of Bio-Oil}

The storage stability of the bio-oil was studied to assess its change in physical properties i.e. viscosity after storing it at room temperature. The accelerated and natural aging methods were used to assess the stability of bio-oil as suggested by Meng et al. [53]. The fresh maize straw bio-oil viscosity was recorded $21.01 \mathrm{cSt}$, whereas for accelerated aging method it was stored at $80^{\circ} \mathrm{C}$ for $24 \mathrm{~h}$ in an oven, and for natural aging method it was stored at a room temperature for 7 months. Fig. S2 indicated that the accelerated aging method increases bio-oil viscosity from 21.01 to 32.3 cSt in just $24 \mathrm{~h}$ i.e. considered as $1 \mathrm{~d}$. Whereas, in case of natural aging it was found that the viscosity of bio-oil was increased slowly at first few months i.e. from 21.01 to $23.5 \mathrm{cSt}$ in $60 \mathrm{~d}$, and it starts to increase rapidly i.e. from 26.0 to $31.7 \mathrm{cSt}$ in between 120 to $210 \mathrm{~d}$. The result showed that, the wheat straw bio-oil viscosity changes from 21.01 to $32.3 \mathrm{cSt}$, when stored at higher temperature of $80^{\circ} \mathrm{C}$ and on the other hand it took approximately 7 months i.e. $210 \mathrm{~d}$, when stored at room temperatures. However, the study conducted by Oasmaa and Kuoppala [54] reported that the increase in viscosity after $6 \mathrm{~h}$ at $80^{\circ} \mathrm{C}$ temperature was found similar to that of 4 month at room temperature.

\subsection{Cost Analysis}

The cost analysis is the act of breakdown a cost summary into its different parts. The detail calculations of cost analysis of the developed system was presented in our previous research article for the wheat straw feedstock [28]. However, the cost analysis parameters such as payback period, NPW, BC ratio and IRR varies with type of feedstock used for fast pyrolysis. In the present study, cost analysis of bio-oil production from maize straw in a fluidized bed reactor was carried out. The developed system is considered to be operated for $300 \mathrm{~d}$ in a year. The system has capacity of processing $50 \mathrm{~kg} / \mathrm{d}$ of maize straw and produces bio-oil and biochar 6,690 L/yr. and $4650 \mathrm{~kg} / \mathrm{yr}$., respectively. The initial investment of the fast pyrolysis system is around 8,626.88 US\$ (1 US\$ = 69.55 INR as on March, 31 2019). The calculated production cost of bio-oil is $0.47 \mathrm{US} \$ / \mathrm{L}$ and the market value of bio-oil is assumed as $0.60 \mathrm{US} \$ / \mathrm{L}$ using previous literature [55]. The produced biochar market value is also assumed as $1.07 \mathrm{US} \$ / \mathrm{kg}$ [56]. By selling the bio-oil and biochar at these market value, the payback period of the system is calculated as 1.47 year. The benefit cost ratio of the project is 1.98, which indicates, system can deliver a positive net present value. However, the net present worth (NPW) and internal rate of return for the present work are calculated as 27, 527.5 US\$ and $68.82 \%$, respectively. With comparing to the previous study [28] and [57], it is clear that the system capacity affect the production cost and assures the good return on investment by selecting a suitable type of feedstock. The all-economic parameters are presented in Table S2.

\section{Comparison of Present Work with Similar Studies}

The comparison of present work, i.e., bio-oil production form maize straw in a continuous fluidized bed reactor, was carried out with recently published similar work as presented in Table S3. It is observed that agriculture residues has found as practical choice to produce bio-oil [33, 58]. Madhu et al. [59] performed the fast pyrolysis of cotton shell in a fluidized bed reactor at a laboratory scale. The maximum bio-oil and char yield of $51.2 \%$ and $18.4 \%$, respectively obtained at a temperature of $450^{\circ} \mathrm{C}$. Due to the lower ash content available in the cotton shell, the yield of bio-oil found more. However, from our previous study Paul et al. [28], it is observed that the wheat straw yields maximum bio-oil yield of $42.0 \%$ at a temperature of $500^{\circ} \mathrm{C}$ and the cost of production of bio-oil per liter was determined as 0.5 US\$. The volatile matter and ash content of biomass feedstocks has the major effect on the pyrolysis product distribution. Sahoo et al. [11] performed the fast pyrolysis of wheat straw at a laboratory scale i.e. $5 \mathrm{~g} / \mathrm{h}$ in a fixed bed reactor. The maximum bio-oil yield of $37.2 \%$ from wheat straw was obtained 
at a temperature of $550^{\circ} \mathrm{C}$ and particle size of $0.5 \mathrm{~mm}$.

In addition Ali et al. [43] performed the fast pyrolysis of maize straw in a fluidized bed reactor with feeding capacity of $2 \mathrm{~kg} / \mathrm{h}$. The maximum bio-oil yield of $42.0 \%$ was achieved at a pyrolysis temperature of $490^{\circ} \mathrm{C}$ and biomass particle size of $1.0 \mathrm{~mm}$. However, $\mathrm{Fu}$ et al. [60] investigated the fast pyrolysis of three agricultural residues such as maize straw, wheat straw and cotton stalk in a v-shaped drop tube reactor. The results revealed that the maize straw gave the maximum bio-oil yield of $46.0 \%$, higher than the wheat and cotton stalk at pyrolysis temperature of $500^{\circ} \mathrm{C}$. Therefore, it is observed that the results of present study in terms of bio-oil quality and quantity is found better than the Ali et al. [40], Sahoo et al. [11] and nearly similar with Fu et al. [60]. The cost economics is the most vital factor, which can help to extend the research work of fast pyrolysis of agricultural residue from laboratory to commercial scale. However, the cost economics of bio-oil production is presented in a very few research articles.

\section{Future Work and Recommendations}

Although fast pyrolysis is proven technology, but the produced bio-oil has some poor properties that limits its application as a fuel. The bio-oil properties like high water content, low $\mathrm{pH}$, high viscosity, corrosiveness, and low heating value affecting the direct application of bio-oil. Generally, bio-oil contains water in the range of (15-50\%) and as suggested in bio-oil norms and standard ASTM D 7544, the grade D and G type bio-oil with $25-30 \%$ is allowable to use as fuel in the turbine and boiler. In spite of above-mentioned limitations, bio-oil can be used as fuel mainly for producing electricity, heat and in engine [61]. However, it is obsevred that more extensive research is required in the field of bio-oil application and upgradation techniques to improve the quality of bio-oil.

\section{Conclusions}

The present work was designed to study the feasibility of maize straw as feedstock for bio-oil production at the pilot scale. The fluidized bed pyrolysis reactor with a throughput capacity of 5 $\mathrm{kg} / \mathrm{h}$ was used. The maximum bio-oil and biochar yield of 44.6 and 31.0 wt.\% were achieved at a temperature of $500^{\circ} \mathrm{C}$, the biomass particle size of $1 \mathrm{~mm}$, and a nitrogen flow rate of $4.0 \mathrm{~m}^{3} / \mathrm{h}$. The produced bio-oil was characterized to identify its fuel and chemical value with the help of GC-MS and FTIR analysis. The maize straw bio-oil possess the heating value of $18.5 \mathrm{MJ} / \mathrm{kg}$ and contains chemical compounds such as phenol (22.83\%), carboxylic acids $(27.36 \%)$, ketone (19.14\%) alcohols (2.09\%), esters, furfural, hydrocarbon and aromatic compounds etc. The techno-economics of the system concluded that biofuel production from maize straw at the pilot scale was an economical approach. The detailed investigation showed that the utilization of agricultural waste into biofuel not only provide sustainable fuel system but also solves the problem of agricultural waste disposal. In future, more research on the production and upgradation of bio-oil at an economical rate is required, and it will help to build a robust biofuel market.

\section{Acknowledgement}

The authors are grateful to Indian Council of Agricultural Research, Govt. of India for providing financial aid to complete the research project. The author (Arjun Sanjay Paul) is also thankful to Council of Scientific and Industrial Research (CSIR) for providing the research fellowship.

\section{Author Contributions}

A.S.P. (Ph.D. Student) conducted the research and investigation process and wrote the original draft. N.S.R (Vice Chancellor) supervised and conceptualization the data. N.L.P (Assistant Professor) supervised the student, wrote and edited the manuscript.

\section{References}

1. International Energy Agency (IEA), [internet] The Global Energy and $\mathrm{CO}_{2}$ Status Report. [cited 10 June 2020] Available from: https://www.iea.org/events/global-energy-co2-status-report.

2. International Energy Agency (IEA), [internet] Renewables 2019 Paris. [cited 12 June 2020] Available from: https://www.iea.org/reports/renewables-2019.

3. Montoya JI, Chejne F, Castillo ME, Acero RJ, Gómez CA, Sarmiento JA. Pirólisis rápida de biomasa. Universidad Nacional de Colombia, Medellín, Colombia, 2013.

4. Global Bioenergy Statistics, [internet] World Bioenergy Association. [cited 10 July 2020] Available from: https://worldbioenergy.org/uploads/191129\%20WBA\%20GBS\%202019_ HQ.pdf.

5. Wankhade RD, Bhattacharya TK. Pyrolysis oil an emerging alternate fuel for future. J. Pharmacogn Phytochem. 2017;6(6): 239-243.

6. Jaidka M, Bathla S, Kaur R. Improved Technologies for Higher Maize Production. In: Maize-Production and Use. IntechOpen. 2019.

7. Wojcieszak D, Przybył J, Dach J, Zaborowicz M, Staszak Ż. Economic assessment of the technology harvesting maize straw for biogas production. BIO Web Conf. 2018;10:1-4.

8. Dupont C, Chiriac R, Gauthier G, Toche F. Heat capacity measurements of various biomass types and pyrolysis residues. Fuel 2014;115:644-651.

9. Garlock RJ, Chundawat SP, Balan V, Dale BE. Optimizing harvest of corn stover fractions based on overall sugar yields following ammonia fiber expansion pretreatment and enzymatic hydrolysis. Biotechnol Biofuels. 2009;2(1):29.

10. Dinesh M, Charles UP, Philip HS. Pyrolysis of wood/biomass for bio-oil: a critical review. Energy Fuels. 2006;20(3):848-889.

11. Sahoo K, Kumar A, Chakraborty JP. A comparative study on valuable products: bio-oil, biochar, non-condensable gases from pyrolysis of agricultural residues. J. Mater. Cycles Waste Manag. 2020;24:1-9.

12. Gamliel DP, Wilcox L, Valla JA. The effects of catalyst properties on the conversion of biomass via catalytic fast hydropyrolysis. Energy Fuels. 2017;31(1):679-687. 
13. Bridgwater AV. Review of fast pyrolysis of biomass and product upgrading. Biomass Bioenergy. 2012;38:68-94.

14. Abdelnur PV, Vaz BG, Rocha JD, de Almeida MB, Teixeira MA Pereira RC. Characterization of bio-oils from different pyrolysis process steps and biomass using high-resolution mass spectrometry. Energy Fuels. 2013;27(11):6646-6654.

15. Chiaramonti D, Bonini M, Fratini E, et al. Development of emulsions from biomass pyrolysis liquid and diesel and their use in engines - Part 2: tests in diesel engines. Biomass Bioenergy. 2003;25(1):101-111.

16. Crayford AP, Bowen PJ, Kay, PJ, Laget H. Comparison of gas-oil and bio-oil spray performance for use in a gas turbine. In: Turbo Expo: Power for Land, Sea, and Air. June 14-18, 2010: Glasgow, UK: 2010. p. 659-667.

17. Czernik S, Bridgwater AV. Overview of applications of biomass fast pyrolysis oil. Energy Fuels. 2004;18(2):590-598.

18. Laird DA, Brown RC, Amonette JE, Lehmann J. Review of the pyrolysis platform for coproducing bio-oil and biochar. Biofuel Bioprod. Bior. Biorefining. 2009;3(5):547-562

19. Liu R, Deng C, Wang J. Fast pyrolysis of corn straw for bio-oil production in a bench-scale fluidized bed reactor. Energ Source Part A. 2009;32(1):10-19.

20. Cai W, Liu R. Performance of a commercial-scale biomass fast pyrolysis plant for bio-oil production. Fuel 2016;182:677-686

21. Treedet W, Suntivarakorn R. Design and operation of a low cost bio-oil fast pyrolysis from sugarcane bagasse on circulating fluidized bed reactor in a pilot plant. Fuel Process Technol. 2018;179:17-31

22. Rout T, Pradhan D, Singh RK, Kumari N. Exhaustive study of products obtained from coconut shell pyrolysis. J. Environ. Chem. Eng. 2016;4(3):3696-3705.

23. Wang XH, Chen HP, Yang HP, Dai XM, Zhang SH. Fast Pyrolysis of Agricultural Wastes in a Fluidized Bed Reactor. In: Yue G., Zhang H., Zhao C., Luo Z, eds. Proceedings of the 20th International Conference on Fluidized Bed Combustion. Berlin: Springer; 2009.

24. Ali N, Saleem M, Shahzad K, Chughtai A. Bio-oil production from fast pyrolysis of cotton stalk in fluidized bed reactor. Arab J. Sci. Eng. 2015;40(11): 3019-3027.

25. Duman G, Okutucu C, Ucar S, Stahl R, Yanik J. The slow and fast pyrolysis of cherry seed. Bioresour Technol. 2011;102: 1869-1878

26. Alper K, Tekin K, Karagöz S. Pyrolysis of agricultural residues for bio-oil production. Clean Technol. Environ. 2014;17(1): 211-223

27. Basu P. Biomass gasification, pyrolysis and torrefaction: practical design and theory. Academic press; 2018.

28. Paul AS, Panwar NL, Salvi BL, Jain S, Sharma D. Experimental investigation on the production of bio-oil from wheat straw. Energ Source Part A. 2020;1-16.

29. Eke J, Onwudili JA, Bridgwater AV. Influence of Moisture Contents on the Fast Pyrolysis of Trommel Fines in a Bubbling Fluidized Bed Reactor. Waste Biomass Valorization. 2019;1-12.

30. Chiaramonti D, Oasmaa A, Solantausta Y. Power generation using fast pyrolysis liquids from biomass. Renew. Sust. Energ. Rev. 2007;11(6):1056-1086

31. Pütün AE, Özbay N, Önal EP, Pütün E. Fixed-bed pyrolysis of cotton stalk for liquid and solid products. Fuel Process Technol. 2005;86(11):1207-1219.

32. Braga RM, Melo DM, Aquino FM, et al. Characterization and comparative study of pyrolysis kinetics of the rice husk and the elephant grass. J. Therm. Anal. Calorim. 2014;115(2): 1915-1920.

33. Hawash SI, Farah JY, El-Diwani G. Pyrolysis of agriculture wastes for bio-oil and char production. J. Anal. Appl. Pyrolysis. 2017;124:369-372.

34. Montoya JI, Valdés C, Chejne F, et al. Bio-oil production from Colombian bagasse by fast pyrolysis in a fluidized bed: An experimental study. J. Anal. Appl. Pyrolysis. 2015;112:379-387.

35. Zhao C, Jiang E, Chen A. Volatile production from pyrolysis of cellulose, hemicellulose and lignin. J. Energy Inst. 2017;90(6): 902-913.

36. Mythili R, Subramanian P, Uma D. Biofuel production from Prosopis juliflora in fluidized bed reactor. Energ. Source Part A. 2017;39(8):741-746.

37. Safdari MS, Rahmati M, Amini E, et al. Characterization of pyrolysis products from fast pyrolysis of live and dead vegetation native to the Southern United States. Fuel 2018;229:151-166.

38. Raja SA, Kennedy ZR, Pillai BC, Lee CL. Flash pyrolysis of jatropha oil cake in electrically heated fluidized bed reactor. Energy 2010;35(7):2819-2823.

39. Onay O, Kockar OM. Slow, fast and flash pyrolysis of rapeseed. Renew Energy. 2003;28(15):2417-2433.

40. Madhu P, Kanagasabapathy H, Manickam IN. Cotton shell utilization as a source of biomass energy for bio-oil by flash pyrolysis on electrically heated fluidized bed reactor. J. Mater. Cycles Waste. 2016;18(1):146-155.

41. Mani T, Murugan P, Abedi J, Mahinpey N. Pyrolysis of wheat straw in a thermogravimetric analyzer: effect of particle size and heating rate on devolatilization and estimation of global kinetics. Chem. Eng. Res. Des. 2010;88(8):952-958.

42. Bridgwater AV, Peacocke GVC. Fast pyrolysis processes for biomass. Renew Sust. Energ. Rev. 2000;4(1):1-73.

43. Ali N, Saleem M, Shahzad K, Hussain S, Chughtai A. Effect of operating parameters on production of bio-oil from fast pyrolysis of maize stalk in bubbling fluidized bed reactor. Pol. J. Chem. Technol. 2016;18(3):88-96.

44. Luo Z, Wang S, Liao Y, Zhou J, Gu Y, Cen K. Research on biomass fast pyrolysis for liquid fuel. Biomass Bioenergy. 2004;26(5):455-462.

45. Lehto J, Oasmaa A, Solantausta Y, Kytö M, Chiaramonti D. Review of fuel oil quality and combustion of fast pyrolysis bio-oils from lignocellulosic biomass. Appl. Energy. 2014;116: 178-190.

46. Grierson S, Strezov V, Shah P. Properties of oil and char derived from slow pyrolysis of Tetraselmis chui. Bioresour. Technol. 2011;102(17):8232-8240.

47. Demiral İ, Eryazıcı A, Şensöz S. Bio-oil production from pyrolysis of corncob (Zea mays L.). Biomass Bioenergy. 2012;36: 43-49.

48. Madhu P, Livingston TS, Kanagasabapathy H. Flash pyrolysis of lemon grass (Cymbopogon flexuosus) for bio-oil production in an electrically heated fluidized bed reactor. Waste Biomass Valorization. 2018;9(6):1037-1046. 
49. Abnisa F, Daud WW, Husin WNW, Sahu JN. Utilization possibilities of palm shell as a source of biomass energy in Malaysia by producing bio-oil in pyrolysis process. Biomass Bioenergy. 2011;35(5):1863-1872.

50. Ren S, Ye XP, Borole AP. Separation of chemical groups from bio-oil water-extract via sequential organic solvent extraction. J. Anal. Appl. Pyrolysis. 2017;123:30-39.

51. Hu X, Mourant D, Gunawan R, et al. Production of value-added chemicals from bio-oil via acid catalysis coupled with liquid-liquid extraction. RSC Adv. 2012;2(25):9366-9370.

52. Zhang XS, Yang GX, Jiang H, Liu WJ, Ding HS. Mass production of chemicals from biomass-derived oil by directly atmospheric distillation coupled with co-pyrolysis. Scientific Reports. 2013;3:1120.

53. Meng J, Moore A, Tilotta DC, Kelley SS, Adhikari S, Park S. Thermal and storage stability of bio-oil from pyrolysis of torrefied wood. Energy Fuels. 2015;29(8):5117-5126.

54. Oasmaa A, Kuoppala E. Fast pyrolysis of forestry residue. 3. Storage stability of liquid fuel. Energy Fuels 2003;17(4): 1075-1084.

55. Wang WC, Jan JJ. From laboratory to pilot: design concept and techno-economic analyses of the fluidized bed fast pyrolysis of biomass. Energy 2018;155:139-151.

56. Pawar A, Panwar NL. Experimental investigation on biochar from groundnut shell in a continuous production system. Biomass Conv. Bioref. 2020;1-11.

57. Jaroenkhasemmeesuk C, Tippayawong N. Technical and economic analysis of a biomass pyrolysis plant. Energy Procedia. 2015;79:950-955

58. Biswas B, Pandey N, Bisht Y, Singh R, Kumar J, Bhaskar T. Pyrolysis of agricultural biomass residues: Comparative study of corn cob, wheat straw, rice straw and rice husk. Bioresour. Technol. 2017;237:57-63.

59. Madhu P, Manickam IN, Kanagasabapathy H. Production and upgradation of cotton shell pyrolytic oil for biofuel from flash pyrolysis by fluidized bed reactor. Proc. Natl. Acad. Sci., India, Sect. A Phys. Sci. 2015;85(3):457-462.

60. Fu P, Yi W, Li Z, Li Y. Comparative study on fast pyrolysis of agricultural straw residues based on heat carrier circulation heating. Bioresour. Technol. 2019;271:136-142.

61. Panwar NL, Paul AS. An overview of recent development in bio-oil upgrading and separation techniques. Environ. Eng. Res. 2021;26(5):200382. 